\title{
Sustainable building solutions: a review of lessons from the natural world
}

Article

Accepted Version

Godfaurd, J., Clements-Croome, D. and Jeronimidis, G. (2005) Sustainable building solutions: a review of lessons from the natural world. Building and Environment, 40 (3). pp. 319-328. ISSN 0360-1323 doi: https://doi.org/10.1016/j.buildenv.2004.05.011 Available at https://centaur.reading.ac.uk/12162/

It is advisable to refer to the publisher's version if you intend to cite from the work. See Guidance on citing.

To link to this article DOI: http://dx.doi.org/10.1016/j.buildenv.2004.05.011

Publisher: Elsevier

All outputs in CentAUR are protected by Intellectual Property Rights law, including copyright law. Copyright and IPR is retained by the creators or other copyright holders. Terms and conditions for use of this material are defined in the End User Agreement.

\section{www.reading.ac.uk/centaur}

\section{CentAUR}

Central Archive at the University of Reading 
Reading's research outputs online 


\title{
Sustainable building solutions: a review of lessons from the natural world
}

\author{
Godfaurd John*, Derek Clements-Croome, George \\ Jeronimidis
}

School of Construction Management and Engineering, The University of Reading, Whiteknights P.O. Box 219, Reading RG6 6AW, UK

*_Corresponding author. Tel.: +44-0-118-378-8201; fax: +44-0-118-931-3856.

E-mail addresses: g.a.john@reading.ac.uk (G.John), d.j.clements-croome@reading.ac.uk (D. Clements-Croome).

\begin{abstract}
The realisation that much of conventional, modern architecture is not sustainable over the long term is not new. Typical approaches are aimed at using energy and materials more efficiently. However, by clearly understanding the natural processes and their interactions with human needs in view, designers can create buildings that are delightful, functional productive and regenerative by design. The paper aims to review the biomimetics literature that is relevant to building materials and design. Biomimetics is the abstraction of good design from Nature, an enabling interdisciplinary science, particularly interested in emerging properties of materials and structures as a result of their hierarchical organisation. Biomimetics provides ideas relevant to: graded functionality of materials (nano-scale), adaptive response (nano-, micro-, and macro-scales), integrated intelligence (sensing and actuation at all scales), architecture and additional functionality. There are many examples in biology where emergent response of plants and animals to temperature, humidity and other changes in their physical environments is based on relatively simple physical principles. However, the implementation of design solutions which exploit these principles is where inspiration for man-made structures should be. We analyse specific examples of sustainability from Nature and the benefits or value that these solutions have brought to different creatures. By doing this, we appreciate how the natural world fits into the world of sustainable buildings and how as building engineers we can value its true application in delivering sustainable building.
\end{abstract}

Keywords: Sustainability; Biomimetics; Sustainable building; The natural world

\section{Introduction}

Biologists and building technologists generally inhabit different worlds. Science studies, proposes hypotheses and collect proof. The technologist applies, innovates and deploys through design. However, it is not self- evident that there are advantages to designers and constructors of the built environment in copying nature, beyond engaging in a fascinating intellectual pursuit. By understanding and engaging the processes of creating the built environment it is possible to seek inspiration from Nature not only about materials and mechanisms but about risk. The natural world has an immense amount to tell us about how 
to achieve sustainability. It uses energy far more efficiently and effectively and is capable of producing materials and structures that are far more benign than anything we have achieved in industry. William McDonough (New Scientist, 20 March, 46-49, 2004) [22] asks the question Why can't a building be designed like a tree? He believes the tree model makes a very tantalising and exciting prospect for a building, which could make oxygen, sequester carbon dioxide, distilled water, build soil, accrue solar energy, create micro-climates, change colour with the seasons and self-replicate.

McDonough also describes the lessons he learnt when he spent time with the Bedouins in Jordan. They wear layers of black clothing in temperatures of over $39^{\circ} \mathrm{C}$. The Bedouins protect themselves in this way from the sun's ultraviolet radiation besides holding their own moisture and increasing convection currents around the body. The average Bedouin lives in a litre of water a day, whereas other people need many times that amount to survive. McDonough also points out that their tents are made of loosely woven goat hair which makes a very responsive tent. Buoyancy increases as the tent gets hot and sucks air through the loose weave. When it is raining the goat fibres swell up and the tent gets very tight. Hugh Aldersey-Williams [1] in his book Zoo- morphic rightly stated that:

The attraction of biomimetics for architects is that it raises the prospect of closer integration of form and function (in this light, biomimetic architecture is seen as an extension of modernism). It promises to yield new means by which buildings respond to, and interact with, their users-means more subtle and more satisfying than present mechanical systems. At a deeper level, according to George Jeronimidis of the University of Reading, architects are drawn to the field 'because we are all part of the same biology'. The urge to build in closer sympathy with Nature is, he believes, a genuinely biological, and not merely a Romantic, urge.

However, there are a number of barriers to interpreting and understanding the topic from the perspective of buildings, other structures and mechanisms. These barriers include: design to satisfy complex code requirements; the linear nature of structural materials that are in common use today; the way that construction industry develops things separately and then joins things together; 'fail safe' structures; and the fragmented nature of procurement and assembly of complex projects and the associated mitigation of risk by all parties [2].

Biomimetics on the other hand, seeks ideas from Nature and then applies them to a problem. For example, the origins of Velcro are famously associated with this way of discovery and application. It is in the solution to difficult and seemingly intractable problems that a building technologist will look to for wider inspirations, including those from Nature. Biomimetics is at the interface of three different disciplines and so requires understanding from biologist biophysics and material science. It is clear that open minds and interactive dialogue will bring enlightenment about problems and opportunities.

Biology has had to solve engineering problems since the appearance of life on earth. Design and functions displayed in plants and animals have evolved over millions of years. These long lead times do not fit easily with the more frenetic pace of the engineering world today but to dismiss the solutions that Nature has arrived at on these grounds would be foolish and arrogant. The time scale may be different but design constraints and objectives 
are similar: functionality, optimisation and economy of scale effectiveness. Some early examples of engineering structures which borrowed ideas from Nature include the Eiffel Tower and Crystal Palace. To abstract ideas from biology and turn them into practical engineering solutions requires all disciplines to contribute [3]. Frei Otto, at the Institute for Lightweight Structures, University of Stuttgart, followed a strict and extensive programme of bringing, architects and engineers together in order to extract useful ideas from biology. Otto's tensile web structures that used to cover the Olympic Stadium in Munich demonstrated this [3].

This paper will touch on various aspects of sustain- ability, but will concentrate primarily on those related to building materials properties, building envelope, environ- mental considerations, sensors and monitoring, team integration and functionality. These areas are seen as the main building blocks for delivering sustainable buildings.

\section{Sustainable buildings}

According to the OECD Project, Sustainable buildings [4] can be defined as those buildings that have minimum adverse impacts on the built and natural environment, in terms of the buildings themselves, their immediate surroundings and the broader regional and global settings. Sustainable buildings may be defined as building practices, which strive for integral quality (including economic, social and environmental perfor-mance) in a broad way. Thus, the rational use of natural resources and appropriate management of the building stock will contribute to saving scarce resources, reducing energy consumption, and improving environmental quality. The OECD project identified five objectives for sustainable buildings;

1. Resource efficiency;

2. Energy efficiency (including greenhouse gas emissions reduction);

3. Pollution prevention (including indoor air quality and noise abatement);

4. Harmonisation with environment;

5. Integrated and systemic approaches.

Sustainable building involves considering the whole life of buildings, taking environmental quality, functional quality and future values into account. Sustain- able building design is therefore the thoughtful integration of architecture with electrical, mechanical and structural engineering resources. In addition to express concern for the traditional aesthetics of massing, orientation, proportion scale, texture, shadow and light, the facility design team needs to be concerned with long-term costs: environmental, economic and human. Buildings contribute to the quality of life much more than we realise.

There are changes in the environment surrounding building design that encourages an alternative and integrated approach. As sustainability increasingly impacts upon the lives of corporations, individuals and wider society, the opportunities for responsible and holistic thinking is also increasing. There are four main targets for applying biomimetics to industrial sustain- ability: through energy and resource efficiency, elimination and control of hazardous substances, use of renewable and biological materials and added functionality in materials and structures [5]. 
3. Properties of building materials and materials of the natural world

Building materials must serve their intended function not only when newly installed but also for some acceptable length of time. Their service life may last for the life of the building or, as with paints, for only a few years before renewal. The durability or the useful life of a material in place, however, is always related to the particular combination of environmental factors to which it is subjected, so that durability, or service life, must always be related to the particular conditions involved. Most building materials are complex in their chemical and physical natures.

The chemical nature of materials is seldom meaningful to the material user or specifier because they do not understand its implications. It is its chemical nature; however, that determines the reactivity of a material to other materials and to some elements of the environment. For example, volatile organic compounds are emitted by some material affecting indoor air quality. The designer needs a sense of chemistry to appreciate the basic difference in the classes and types of materials. It is especially significant that small changes in composition (even trace amounts of some substances, as with metal alloys) can have a profound influence on the resulting properties. For example, the influence of ultraviolet radiation on organic materials can be appreciated when it is known that the organic molecule has bonds that can be broken and that other changes can be induced through action of solar radiation. This does not happen with metals or cementituous materials [6].

It is customary in structural design to consider a material in terms of the practical unit in the total structure, whether it be a beam, column or plate. The engineering properties are given in terms of the bulk material, the assumption is made that the material is homogenous and isotropic on a scale that is significant in the proposed design. This manner of thinking about a material does not allow for an understanding of its behaviour because at this scale the factors that determine the response of the material itself cannot be appreciated. It is like considering the response of a steel bridge to a given load without being able to analyse the stress in any one member. The bridge may carry a certain load but it may fail in time if one member is overstressed.

To understand the physical and mechanical behaviour of a material it is necessary to think of the material on a micro-structure scale. Consideration must be given to the grain, defined by crystalline or polymer molecules, the assemblage of these into the many geometric arrangements that occur, the space or porosity around them and the nature and extent of the 'bonds', or forces that hold these building blocks together.

A parallel study of basic biological materials, shows the chemical substances used by organisms to provide the properties needed for the various mechanical functions. It is interesting to note that they are comparatively few, far fewer in fact than what are available to the engineering community. They do not have any especially outstanding characteristics and, compared to many engineering materials, none of them has a particularly high Young's modulus, tensile strength or toughness. In other words they cannot be classed as 'high-performance materials', though they do have much lower 
densities than most. They are successful not so much because of what they are but because of the way in which they are combined to operate. Extremely successful engineering solutions do not require esoteric and expensive materials.

Inspired by biological systems in which damage triggers an autonomic healing response, researchers at the University of Illinois have developed a synthetic material that can heal itself when cracked or broken. Once crack has formed within typical polymeric, the integrity of the structure is significantly compromised. Often these cracks occur deep within the structure where detection is difficult and repair is virtually impossible. In the new material, the repair process begins as soon as a crack forms. When the material cracks, the microcapsules rupture and release the heating agent into damaged region through capillary action. Filling the micro-cracks will also mitigate the harmful effects of environmentally assisted degradation such as moisture swelling and corrosion cracks. This technology could increase the lifetime of structural components, perhaps by as much as two or three times. The ability to self- repair and restore structural integrity also could extend the lifetimes of polymer composite circuit boards, where micro-cracks can lead to both mechanical and electrical failure [7].

Rematerialisation in the industrial world refers to chemical recycling that adds value to materials, allowing them to be used again and again in high-quality

products. This process suggests a design strategy aimed at maximising the positive effects of materials and energy and participating in the Earth's abundant material flows cycle. Nylon 6 provides a good example of rematerialisation. This widely used polymer can be chemically recycled into raw material caprolactum, which can be used to make generation after generation of high-quality carpet fibre. The process virtually eliminates waste with less energy than having to use virgin materials or material lost. Given the hundreds of millions of pounds of carpet fibre that each year are sent to landfills or incinerators or recycled into products of lesser value, the significance of rematerialising nylon 6 is enormous. It suggests a new model for material flow that will change real-world business [8].

It is a fact of life that nearly all load bearing materials in nature are fibrous composites of some kind or another. The use of fibres for making structural materials offers a great deal of scope and flexibility in design but it also presents a few problems. A major problem with fibre is that they are most efficient when they carry pure tensile loads, either as structures in their own right (ropes, cables, tendons, silk threads in spider's web) or as reinforcement in composite materials used as membrane structures in biaxial tension. This problem is common to both man-made and biological composites. There are four solutions available to this problem in Nature: Pre-stress the fibre in tension so that they hardly ever experience compressive loads; introduce high modulus mineral phases intimately connected to the fibres to help carry compression; heavily cross-link the fibre network to increase lateral stability, and change the fibre orientation so that compressive loads do not act along the fibres [3]. One important aspect of fibrous systems is that they provide greater opportunities for added functionality because there is no obvious dividing line between materials and structures.

Experience with traditional materials over many years permits prediction of the performance of the same material under similar conditions. Such trials have provided an answer to how but not often why materials react as they do. When new materials are to be 
developed or considered or when traditional materials are to be used in an untried situation, the ability to predict may be greatly limited unless the 'why' of past experience, and thus the fundamental factors involved are understood. This is basic to the exercise of judgement in design, which is a combination of experience and analysis [9]. Such an approach is also necessary in the development and interpretation of new methods designed to improve new materials perfor- mance. Exact prediction of performance requires a complete understanding of material properties, the processes involved in the interaction of the materials with its environment, and the environmental factors to which it will be subjected. Careful selection of environmental sustainable building materials is the easiest way for architects to begin incorporating sustainable design principles in buildings. Natural materials are generally lower in embodied energy and toxicity than man-made materials. They require less processing and are less damaging to the environment. When low-embodied- energy natural materials are incorporated into building products, the products become sustainable.

\section{The building envelope}

The building envelope includes all the building components that separate the indoors from the out- doors. The envelope of the building consists of the exterior walls, the roof, floors, windows and doors. In addition to giving the wall the desired appearance, the envelope must withstand the stresses to which it is exposed and also must protect the enclosed space against the local climate. It also acts as a climate moderator. Designs for exterior walls for buildings have seldom been developed in a systematic, rational way. They have evolved slowly, keeping pace with gradual changes in social and economic patterns and environ- mental requirements $[2,10]$. Today, with dynamic architecture and many new materials, components and construction techniques available, a large number of new designs are possible. Unfortunately, some are being adopted without adequate consideration, and evaluation by the slow trial by use methods of the past is no longer adequate.

It is now possible with the aid of building science to recognise the pertinent factors affecting the performance of walls and to analyse wall designs systematically as to their probable performance in respect of their varied requirements. With this capability one may begin to discriminate between various designs for particular uses, and, even important to provide a basis for the development of improved designs.

It is important, at the outset, to recognise that the over-all function of an exterior wall or roof, in conjunction with floors, is to moderate solar radiation, temperature extremes, moisture (as vapour or liquid), dust and wind. The wall also provides barrier or filter to noise, fire, particulate matter, insects, animals and even human intrusion. It may be required to transmit light (window), while imposing a must contribute suitably to the form and aesthetics of the building generally; and finally must satisfy a number of lesser requirements such as colour, texture and porosity. All of this must be achieved at an acceptable life time cost.

Determination of the outdoor environment and establishment of that desired indoors is 
essential first step in exterior wall design. Only when these factors are known is it possible to assess the overall performance requirements of the wall acting as a separator.

Table 1 Standard $U$-values for current and proposed Building Regulations $\quad \mathrm{W}=\mathrm{m}^{2} \mathrm{KP}$

\begin{tabular}{lllll}
\hline Element & $\begin{array}{l}\text { 1995 standard } \\
\text { U-values }\end{array}$ & $\begin{array}{l}\text { 2000 standard } \\
U \text {-values }\end{array}$ & $\begin{array}{l}\text { Percentage reduction in } \\
\text { U-value (\%) }\end{array}$ & $\begin{array}{l}\text { Thermal } \\
\text { resistance }\end{array}$ \\
\hline Walls & .45 & 0.35 & 22 & 2.86 \\
Roofs & .25 & .16 & 36 & 6.25 \\
Floors & .45 & .25 & 44 & 4.00 \\
Windows & 3.3 & 2.2 & 33 & 0.45 \\
\hline
\end{tabular}

Table 2 The specific heat of several common building materials

\begin{tabular}{llllr}
\hline Material & Density $\left(\mathrm{kg} / \mathrm{m}^{3}\right)$ & Conductivity $(\mathrm{W} / \mathrm{mK})$ & Specific heat $(\mathrm{J} / \mathrm{kg} \mathrm{K})$ & Heat capacity $(\mathrm{kJ}$ \\
\hline Mineral fibre & 25 & .04 & 750 & 20 \\
Carpet & 190 & .06 & 1360 & 260 \\
Fibreboard & 300 & .06 & 1000 & 300 \\
Timber & 630 & .13 & 1200 & 760 \\
Lightweight & 600 & .16 & 1000 & 600 \\
Plasterboard & 950 & .16 & 840 & 800 \\
Brick & 1700 & .62 & 800 & 1360 \\
Medium density & 1400 & .51 & 1000 & 1400 \\
Stone & 2180 & 1.5 & 720 & 1570 \\
Dense concrete & 2300 & 1.9 & 1000 & 2300 \\
Water & 1000 & & 4200 & 4200 \\
\hline
\end{tabular}

Inevitably, at this stage, some aspects of the building services become involved. Through them certain fea- tures of the indoor environment are adjusted to the desired levels. The day lighting characteristics of the transparent portions of the wall must be considered in relation to lighting, and heating and cooling require- ments are related to the nature of the wall as a barrier to solar radiation, heat, moisture and air during both winter and summer. Other barrier requirements such as those related to more dust and smoke may have implications also for the services required. Relative humidity indoors, of moisture condensation in indoor environment and the design of exterior walls for cold weather conditions merits special attention. Durable walls can be achieved by judicious selection of materials to suit the environment, by modification of the environment to suit the materials available, or a combination of both. Such manipulation however, requires an understanding of the pertinent properties of materials and the phenomena that operate within the walls [10].

New regulations to Part $L$ of the Building Regulations came into effect on 1 April 2002; there will be further changes in 2005. As shown in Table 1, the $U$-values have been reduced by up to $44 \%$. In simplistic terms masonry wall will require 65-100 mm, roof will need 200$260 \mathrm{~mm}$, while floors will typically need about $100 \mathrm{~mm}$ insulation. While the Building Regulation concentrate on insulation, they say nothing about the thermal mass of the construction. Combining high levels of insulation with thermal mass has an important role to play in providing low running costs and comfortable internal temperatures. The surfaces around a room absorb and release heat to the room depending on the temperature conditions. From Table 2 it can be seen that generally heat capacity increases with density. 
Also the thermal conductivity increases with density: the denser materials conduct heat faster. Heavyweight building materials such as concrete blocks, brickwork or stone, can absorb large amounts of heat. Lightweight materials, such as timber, insulation or plasterboard are not able to absorb so much heat. An old stone cottage will have a very high thermal mass but the wall $U$-value may be as high as $2 \mathrm{~W}=\mathrm{m}^{2} \mathrm{~K}$ (i.e. 0:50 $\mathrm{m}^{2} \mathrm{~kW}^{-1}$ or 5.0 tog thermal resistance)-six times the proposed wall $U$-value in the revised regulations. To be effective the mass needs to be well connected or 'coupled' with the space. Spreading the mass around the surface is much more effective than having one very heavyweight wall, e.g., with other lightweight partitions. Thus the effectiveness depends on the mass and the area coupled to the space [11,12].

In contrast, Penguins are a specialised group of non- flying aquatic birds that live in the southern hemisphere, most famously in the Antarctic. The ability of some species to withstand extreme cold whilst fasting for up to 120 days has excited much attention. Several studies have investigated the thermal resistance of penguin 'coats' (feather \& skin assembly) and found it to be surprisingly low-an average of $0: 74 \mathrm{~m}^{2} \mathrm{~kW}^{-1}$ or 7.4 tog. Penguin feathers are heavily modified, being short (30-40 $\mathrm{mm})$, stiff and lanced shaped. Insulation is provided by a long $(20-30 \mathrm{~mm})$ after-feather. Penguins are unique in that the feathers are evenly packed over the surface of the body $\left(30-40 \mathrm{~cm}^{-2}\right)$ rather than arranged in tracks. For insulation the penguin requires a thick, air-filled, windproof coat (similar to open-cell foam covered with windproof layer) that eliminates convection and reduces radiation and convective heat losses to a minimum [13]. Perhaps there is a lesson to be learnt here.

An example of this is the way that the modern office developments need to moderate external environment through the facade. In one such building, Plantation Place, London, the Client is a developer, The British Land Company. There are many levels at which the building responds to an environmental and social agenda, but it is in the development of the facade that the principles of biomimetics have been employed.

\section{Environmental consideration}

There is an increasing recognition that buildings cannot be designed without consideration for their social impact on the environment. Waste and pollution for example affects communities. Environment can be defined as the combined effect of a number of factors that interact with the building: temperature, moisture, solar radiation and foreign matter. In effect the environment reacts with the various material components of the building, externally as well as internally. Although these can often be measured separately and recorded quantitatively against basic standards, their significance to the performance of a material lies in the degree of their interaction with the material. The material responds to temperature and its variation inside the material. This may be different from the temperature of the air surrounding the material because of thermal lag and radiant heat loss or gain [6].

Buildings filter the passage of light, air, sound and energy between the inside and outside environments. They also offer the passage of time by the views and shadows they offer to occupants. Buildings provide contrast between interiors and exteriors. The link between 
them is provided by windows. The need for window is complex. It includes the need for natural light, an interesting and contact with the outside world, at a fundamental level, it provides contrast for people working in the office. It also gives one a sense of time. The environment inside buildings is linked to that outside by entrances (or exits), windows and chimneys. The environment inside the building has many facets. There is the support system provided by facilities and various conveniences, besides information and communication systems set up to aid the links between organisation inside and outside of the building. There is the social environment provided by the people themselves and there is the physical environment provided by the things we see, hear, touch, feel and smell.

Issues of sustainability will force us to consider buildings in relationship to towns and cities, and the evaluation of building performance will involve the quality of indoor environments. Since buildings are responsible for half of the nation's energy and hence carbon dioxide emissions, the design, construction and operation of buildings is vitally important for people now and in the future. This of course applies to the entire building stock of old and new buildings [2].

Energy needs to be decreased not only because of the demand that is made on nonrenewable fossil fuels, but because buildings emit large amounts of carbon dioxide and effectively this constitutes almost half of that which is responsible for the greenhouse effect. The environmental effects of other pollutants such as smoke, fumes, chemical and noise is also an issue. The internal environment is important too if people living and working in building are to experience a good sense of well-being and optimal productivity [21].

A lot can be learnt about the response of building materials to their environment by considering the animal world. Termites are some of the most ingenious of animal architects. There are more than 2000 species of termite living in tropical and sub-tropical regions and this is reflected in the variety of dwelling styles that have evolved, but they do have one unifying theme. They all can maintain equilibrium between the heat that the ants release as a community living inside the termitanes and the heat gain and loss through dwelling due to the surrounding climate [14].

In Australia the compass termites build castles in the shape of huge flat chisels always with their long axis pointing north south. Such shapes expose the minimum possible area to the midday heat but catch the rays of the early morning and the late evening sun when the termites need some warmth especially in the cold season; peak temperatures can be lowered by about $7^{\circ} \mathrm{C}$ with such orientation.

Some termites have chimneys, others have rain roofs, but one of the most interesting species are those found on the Ivory Cost of West Africa. A mound might reach a height of 3-4 $\mathrm{m}$ and can contain two million termites. They live, they work and they breathe. Their oxygen consumption is considerable, and without ventilation they would all be suffocated within a few hours, so that ventilation is essential and yet the solid outer surfaces show no signs of openings. These insects have evolved an ingenious ventilation system which cuts vertically through the centre of the mound. There is a royal cell in the centre which has many chambers and passages, between it and the thick outer wall there are ridges with narrow air spaces very much like capillaries in the human blood system. Below it is a large 
air space called a cellar; another air space above it reaches a long way into the centre of the nest like chimney. Channels as thick as an arm radiate from the upper air space into the ridges where they sub-divide in to many small ducts and these come together again to form channels as wide as those leading to the cellar.

The ventilation system is completely automatic and maintains a temperature of about 30 ${ }^{0} \mathrm{C}$ in the nest. The air in the chambers is heated by fermentation processes taking place there, the termites themselves causing a rise in temperature. The hot air rises and is replaced by streams of air from ridges. The exterior and interior walls of these ridges are porous and allow diffusion of carbon dioxide outwards and oxygen permeates in- wards. The ridges with their system of ducts act as lungs for the colony. There is so much debate going on today about indoor air quality and gas emissions and the amount of fresh air that is required for healthy working conditions, but these insects mastered this art many centuries ago.

The City of Seattle in 2002 began an extensive reworking of the Southwest entrance of Key Tower 700 Fifth Avenue building. The new entrance vestibule is designed to improve the flow of pedestrian traffic, increase safety, strengthen the connection between Key Tower and the City's new Civic Centre, and created a new identity for the building. The new entry is an unconditioned vestibule enclosed with glass and bathed in daylight. This rework took advantage of natural ventilation and passive solar, thereby foregoing the need for heating or air conditioning. The Key Tower remodel design team borrowed from one of nature's master architects, the termite, to provide thermal comfort and ventilation in the vestibule without using energy for heating or air conditioning.

The key Tower entrance vestibule uses concrete as thermal mass to store cold during the summer and heat during winter. During the summer, the supply air flows through the concrete chamber under the vestibule. The concrete, cooler than the temperature outside, will cool the air as it flows across its mass. As the air heats up in the vestibule it will naturally rise. Louver vents are located near the roof and exhaust the hot air assisted by a photovoltaic powered ventilation fan. During the winter the system is reversed. The thermal mass heats incoming air and the cold outside air is warmed as it enters by heat stored in the concrete mass. The louver vents located near the roof are closed to keep warm air from escaping, and solar heat gain provides some additional heat during the day. With the help of computer modelling and CFD, this innovative approach used thermal mass, natural ventilation and passive solar design strategies [15].

The strength of vernacular architecture is that it blends buildings into various settings so that there is a natural harmony between climate, architecture and people. In countries such as Iraq, Iran and Egypt there have evolved buildings which not only demonstrate this harmony and unity between people and their environment but also offer a combination of engineering and architecture which has an aesthetic quality.

Built in Northern Ohio at Oberlin College, the Adam Joseph Lewis Centre for Environmental Studies was designed to ultimately generate more energy that it consumes. Solar power is collected through southwest- facing windows into a two-storey atrium, illuminating the public areas. Wastewater is purified by a constructed mesh-like ecosystem that breaks down and digests organic material and releases clean water. The upholstery fabrics will feed the garden, and the carpets will be retrieved by the manufacturers and 
reused for new, high-quality carpets. Lit by the sun, refreshed with fragrant breezes, in tune with its place through the local flows of energy and matter, the Oberlin building's ecological footprint strongly confirms that human presence in the landscape can be positive, restorative and good [8].

Yeang is one of the pioneers in this field. Yeang's designs follow the theme of 'urban ecosystem', a holistic design solution that deals actively with milieu for pedestrian flows, plant growth and the equilibrium of energy, water and waste. Yeang believes that all architecture ought to respond ecologically to the natural environment as a whole. His designs aspire to making a direct contribution to a sustainable ecological future. The combination of engineering and qualitative spatial oversizing oflinked internal and external spaces presents new alternatives for high-rise building: 'ecological' or 'technological'. Although this approach yield buildings that are exceptionally well adapted to their surround- ings, there are certain issues that continually recur in Yeang's oeuvre; and these may be reduced to two points; wind and solar orientation. The wind is known as the 'compass project' and the solar as the 'sunpath projects' [16].

Designs for the compass projects are on the whole fragments and display countless openings to make thorough natural ventilation possible. The design takes account of the prevalent wind direction to ensure that the ventilation is as effective as possible. Furthermore, use is made of a variety of innovative ideas such as wind-wing walls, aerodynamic surfaces and roof-level 'sky courts' to suck in the air. Yeang's sunpath buildings have a number of features in common. Like the compass designs, these projects use natural ventilation wherever possible, even in 'unsuitable' places. The overall design is however dictated by the sun. This goes beyond the placing of glazing and sun barriers: the whole structure is related to the diurnal and annual course of the sun.

He shows how the poetry of everyday life can be 'organised' by the refined application of natural and technical alternatives, developed by interdisciplinary development/design teams. The most important new idea is taking man in his environment as the departure point, variable and criterion. Design teams can develop buildings with alternative attributes for temperature, wind, humidity, daylight and smells. Buildings similarly gain a microclimate that change in accordance with the time and the outdoor conditions, as well as a more pleasant interior, a space that will endure longer than we imagine [17].

In Ken Yeang's green skyscrapers Bishopsgate Towers at Elephant \& castle, London, with characteristic greenery and partly open glazed facades, enclose a variegated programme: apartments, bars, a hotel, restaurant, sport facilities, parks and playgrounds. It is a good example of an inner city project. The towers are built and aligned to take the maximum advantage of passive solar energy. Keeping the large area of the tower open allows sunlight to penetrate deep into the interior and gives the wind an obstructed passage. The aim is to use these limits to create a varied look on each floor, both vertically and horizontally [16].

People in different countries have adapted to different levels of temperature of only some $4{ }^{\circ} \mathrm{C}$ in climates where the diurnal range may be in the order of $17^{\circ} \mathrm{C}$ : There are many ways in which man has adapted to climate whether it is the covered tents commonly found in hot countries; arranging streets so that the buildings are close together, or the use of cloisters or verandahs around the courtyard of buildings to offer shade. What is evident is the attempt to balance basic needs in a simple way but also in a style which is pleasing to the eye 
[14]. However, some of these ideas have been used in modern architecture but there is still scope for more.

\section{Sensors, monitoring and feedback systems}

Thanks to the development of microprocessor electronics, digital systems can be found everywhere in industry from biological engineering to fashion computer design. New, computer-assisted technologies have given birth to interdisciplinary sciences such as computational biology, neural robotics, artificial intelligence and combinational drug production. With a very high signal to noise ratio and negligible error coefficient, digital systems have massively replaced old analogue devices. Still, those systems do not have the information capacity of natural biologic sensors, which are entirely analogue. Biological sensors, operating at the complex nature-animal interface, process gigantic volumes of information in real time. Biological sensors have also a remarkable capability to operate as multifunctional devices. The sensors located in the tips of our fingers are not only touching receptors, they are pressure sensors, sharp memory devices, temperature sensors, and liquid-viscosity sensors as well. The human eye is not just a photographic camera but a complex system for image processing, colour detection, light-intensity calibration, and motion detection. These sensors trans- form mechanical, thermal, and optical energies into electrical signals to the brain, which provides feedback to the sensors through sophisticated pattern recognition procedures. Without the brain's feedback and pattern recognition capabilities, sensors alone would not be able to achieve high resolution, sensitivity and selectivity. Sensors rarely operate in a simple environment where only one parameter changes. Most physical and chemical sensors operate in complex environments where various parameters change simultaneously. The most critical problem is cross-sensitivity [18].

Presently the sensors within building are simple and not all multi-functional. The integration of sensors (e.g. chemical sensors) with others offers new possibilities to decrease the cross-links between adjacent sensors. Advanced sensors for multifunctional applications can be designed on the basis of the integration of new technologies, such as Micro-electro-mechanical systems (MEMS) and thin film technologies. For example, motor racing started sometime in 1896 and the efficiency and reliability of cars have advanced remarkably in the past century. In Formula 1 motor racing, the success of racing car depends on hundreds of components working together at peak performance under the most extreme conditions. Each car carries about $1.5 \mathrm{~km}$ of wiring that pulls data from approximately 120 sensors that are located around the body of the car, providing essential information about performance, orientation or load communicated back to the pit crew by onboard telemetry [19]. Components such as displacement sensors are designed to control and monitor a growing number of vital functions on racing cars and supply information to engineers that help trim precious seconds off the car's lap times. The building industry is yet to achieve this level of monitoring and feedback whereby our building can approach the envisaged sustainable level. However, such technology can be utilised by the industry for effective sustainable solutions. The Building Management System (BMS) monitoring sensors may have to be raised to a standard comparable to those if we are to fine tune our 
approach for sustainable delivery.

Animals large and small have sophisticated sensor systems. Crocodiles have arrays of mechanical sensors near their jaws and over their back so they can detect very small vibrations and thus guide them in defence or attack. Imagine a wall with embedded sensors interacting with detector chips on people so that the indoor climate becomes a system of localised and personalised microclimates. As well as sensor-based systems, it is also worth looking at 'adaptive' response systems where the design at the material/structural levels embeds a specific response triggered by external stimulus. There are several of these in biology, pine cones as one example. Team integration and functionality

A building is a complex product. The technology applied to building involves almost every facet of pure and applied science. Its design and construction requires the involvement of various disciplines and trades. For successful application it must be understood by all whose work touches on buildings: owners, architects, engineers, contractors, material suppliers and operators. Most cannot be expected to have either depth or breadth in the knowledge available. It is clear, therefore, that participants in the building industry require assistance in matching available technology with the specific problems encountered in their day-to-day activities.

One might define a good engineer as someone who is capable of extracting maximum performance at mini- mum cost from the materials available and so achieve a design that is 'fit for purpose'. This has been a recurrent theme in engineering courses since the material science became academically acceptable as a discipline and, together with creativity; they are the yardsticks by which we judge success or failure. All too often, the problem is not with the aims but with the methods we use to achieve them. In particular the fact that our traditional approach to design has been severely limited by the labels we attach to ourselves, or that others see fit to identify us with; engineer (mechanical, structural, civil, materials, medical, aeronautical, transport, electrical, electronic, software). In the same way as in Nature, the boundary between materials and structure is blurred; the study of biological systems to understand those aspects of design that might be useful for our purposes requires an integration of all the disciplines above. The main reason for this is that biological structures are often multifunctional. If we do not understand what the various functions are, and how they are controlled and integrated, it will be difficult to extract any lessons [2].

\section{Discussion and conclusions}

Throughout the paper one theme that emerges is the value of the lessons from Nature that will be applied as technologies emerge and innovation is used to deliver sustainable buildings of the future. The natural world provides an immense database of designs that can inspire creative thoughts. For instance, butterfly scales produce their optical effects via effects such as diffraction, multilayer interference, scattering and fluorescence, all of which are known to the scientific community. However, what is interesting is the way they 
combine these effects in seemingly random ways that would not necessarily occur to the designer [20]. It is important to recognise the valuable contribution made by engineers of all kinds in helping the biologist and the biophysicist to unravel the design principles behind the natural world. It is also the synergy between these disciplines that will provide the means of increasing our understanding of what Nature does and being aware of advantages as well as limitations towards delivering sustainable buildings. Rich rewards lie in a variety of established and emerging technologies, not only in taking the design rules and paradigms offered to us by nature's systems, but also trying to take advantage of some of its selfassembly processes, self-repair process and optimum use of sensors and monitoring of our environment. Sustainable building components are waiting to be discovered and adapted form nature's designs.

Many of these lessons imply actions which impact on and overlap with one another. They should not, therefore simply be each considered in isolation. Many require concerted and integrated action across all aspects of the industry and some require involvement of other sectors, some of which can contribute positively towards future progress and change (financial institutions being one example). Some of the actions proposed, being interdependent, will only result in improvement when some of the other elements on which they depend are in place. Equally, some technologies will take a number of years to reach fruition, yet they need to be planned now. Many of these elements depend on partnering, collaboration and customer involvement. They also demand a different way of thinking about building construction generally, which is an issue that the whole industry needs to respond to. The cost of obtaining new knowledge is not recovered until the knowledge is applied and the added value gained.

\section{References}

[1] Aldersey-Williams H. Zoomorphic: new animal architecture. London: Laurence King Publishing Ltd.; 2003.

[2] Clements-Croome D. Intelligent buildings: design, construction and operation. London: Thomas Telford; 2004.

[3] Jeronimidis G. Biomimetics: lessons from nature for engineering. The 35th John Player Memorial Lecture, The Institution of Mechanical Engineers, 22 March, London, 2000.

[4] OECD. Design of sustainable building policies. Paris: OECD; http://www.uea.ac.uk/env/; 2002.

[5] BIONIS, http://www.extra.rdg.ac.uk/eng/BIONIS/; 2004.

[6] Crawford CB. CBD-200. Building technology and its use. Canadian Building Digest, National Research Council Canada, 1978.

[7] Kloppel L, http://www.azom.com/news.asp?newsID=966); 2001.

[8] McDonough W, Braungart M. Towards a sustaining architecture for the 21st century: the promise of cradle-to-cradle design. UNEP Industry and Environment. April-September 2003. p. 13-6.

[9] Sereda PJ. CBD-115. Performance of building materials. Cana- dian Building Digest, National Research Council Canada, 1969.

[10] Hutcheon NB. CBD-48 Requirements for exterior walls. Canadian Building Digest, Canada Research Council, 1963.

[11] Willoughby J. Using thermal mass to save energy. Journal of The Institution of Structural Engineer 2002;80(12):10-3. 
[12] CIBSE. Guide book-a enviornmnetal design. Thermal response and plant sizing. Chartered Institution of Building Servives Engineers, 1999 [chapter 5].

[13] Dawson C, Vincent JFV, Jeronimidis G, Rice G, Forshaws P. Heat transfer through Penguin feathers. Journal of Theoretical Biology 1999;0959:291-5.

[14] Croome DJ. Building services engineering-the invisible archi- tecture. An abridged version of an Inaugural Lecture given at the University of Reading on Monday 13 February 1989 in the Palmer Theatre, Whiteknights, 1989.

[15] FYI. Sustainable building case study: key tower base remodel. City of Seattle/Department of Design, Construction \& Land Use, http://www.cityofseattle.net/civiccenter/Images/ktbase_Key- Tower-SECTIONB.pdf; 2000.

[16] Ken Yeang. The green skyscraper, the basics for designing sustainable intensive buildings. Munich, London, New York: Prestel Verlag; 1999.

[17] Quanjel EMCJ, Zeiler W, Ken Yeang. Designing with nature. Federation of European Heating and AirConditioning Associa- tions (REHVA) Journal 2003; 13-7.

[18] Ivanov DV. Advanced sensors for multifunctional applications. The following article appears as part of JOM-e, 52 (10), Website: http://www.tms.org/pubs/journals/JOM/0010/lvanov-0010.html; 2000.

[19] Westbury PS. The value of innovation. The Journal of The Institution of Structural Engineer 2004;82(1):33-7.

[20] Lawrence C, Large MCJ. Optical biomimetics, http://www. oftc.usyd.edu.au/docs/biomimetics-textonly.doc; 1999.

[21] Clements-Croome D-J. Creating the productive workplace. Spon Press, 2000.

[22] McDonough W. New Scientist, 20 March 2004. p. 46-9. 